\title{
Moment of Inertia Dependence of Vertical Axis Wind Turbines in Pulsating Winds
}

\author{
Yutaka Hara, ${ }^{1}$ Koichi Hara, ${ }^{1}$ and Tsutomu Hayashi ${ }^{2}$ \\ ${ }^{1}$ Department of Mechanical and Aerospace Engineering, Graduate School of Engineering, Tottori University, 4-101 Minami, \\ Koyama-cho, Tottori 680-8552, Japan \\ ${ }^{2}$ Nagoya Industrial Science Research Institute, 306 Yuta, Obata-cho, Ise, Mie 519-0506, Japan
}

Correspondence should be addressed to Yutaka Hara, hara@damp.tottori-u.ac.jp

Received 5 October 2011; Revised 19 January 2012; Accepted 2 February 2012

Academic Editor: J.-C. Han

Copyright ( $) 2012$ Yutaka Hara et al. This is an open access article distributed under the Creative Commons Attribution License, which permits unrestricted use, distribution, and reproduction in any medium, provided the original work is properly cited.

\begin{abstract}
Vertical Axis Wind Turbines (VAWTs) are unaffected by changes in wind direction, and they have a simple structure and the potential for high efficiency due to their lift driving force. However, VAWTs are affected by changes in wind speed, owing to effects originating from the moment of inertia. In this study, changes in the rotational speed of a small VAWT in pulsating wind, generated by an unsteady wind tunnel, are investigated by varying the wind cycle and amplitude parameters. It is shown that the responses observed experimentally agree with simulations based on torque characteristics obtained under steady rotational conditions. Additionally, a simple equation expressing the relationship between the rotational change width and amplitude of the pulsating wind is presented. The energy efficiency in a pulsating wind remains constant with changes in both the moment of inertia and the wind cycle; however, the energy efficiency decreases when the wind amplitude is large.
\end{abstract}

\section{Introduction}

Vertical Axis Wind Turbines (VAWTs) [1] are promising energy devices [2-4]. They have a simple structure, their output power is unaffected by changes in wind direction, and based on their lift driving force, they have the potential for high efficiency. However, VAWTs are affected by wind speed variation, owing to their moment of inertia. As a result, rotor response to wind speed variation is important when considering the proper control of VAWTs.

In general, for the design, analysis, and control of the more widely prevailing Horizontal Axis Wind Turbines (HAWTs), prediction of unsteady aerodynamic loads is challenging and crucial. For this reason, much effort has been put into modeling the unsteady aerodynamics of wind turbines [5]. In the case of VAWTs, even if the wind speed is constant, the angle of attack of the inflow to a blade periodically changes during rotation. Thus, dynamic analysis of a VAWT is essential for reliable design and reduction of cost [6]. In practice, the problems are even more complex, as the wind turbines are often installed under conditions of turbulence and abrupt wind-speed variations.

Ordinarily, wind turbine performance predictions are compared with field or experimental data measured under constant wind speed. Recently, transient responses were measured for a straight-bladed VAWT subjected to steplike wind speed variation in an unsteady wind tunnel [7]. In the present study, to investigate the dependence of VAWT performance on the moment of inertia in unsteady wind, the response of a straight-bladed VAWT to a pulsating wind is measured, changing the rotor moment of inertia, the wind cycle, and the wind amplitude. The experimental results are compared with a numerical simulation, in which it is assumed that the experimental torque coefficients are obtained under conditions of constant wind speed. Furthermore, a simulation is carried out for a theoretical VAWT with a different rotor size from that used experimentally, and the dependence of the rotor response on the mean speed of the pulsating wind is investigated, as is the behavior of the rotor in the case of a long wind cycle. 


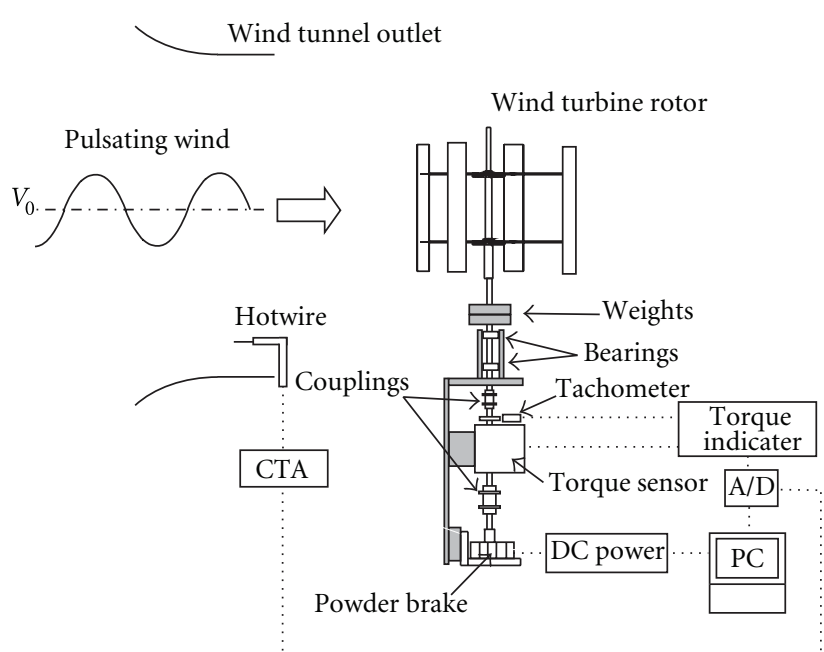

FIGURE 1: Experimental VAWT setup.

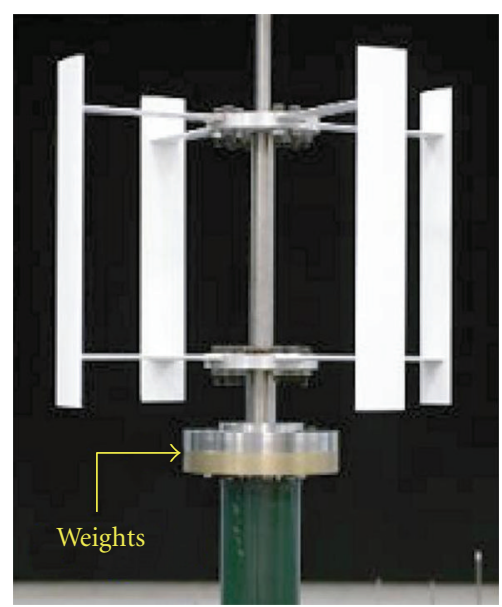

FIGURE 2: Experimental VAWT rotor with weights added to rotational axis to increase the moment of inertia.

\section{Experimental Apparatus}

A schematic of the experimental setup is shown in Figure 1. The experimental VAWT has four straight blades with NACA 0012 airfoils (chord length: $c=0.075 \mathrm{~m}$ ). The rotor diameter is $D=2 R=0.6 \mathrm{~m}$, and the height is $H=0.47 \mathrm{~m}$. The swept area of the rotor is $A=D \times H=0.282 \mathrm{~m}^{2}$. The original moment of inertia of the rotor is $I=0.1 \mathrm{kgm}^{2}$, and this can be increased to up to $0.3 \mathrm{kgm}^{2}$ by fixing weights on the axis under the rotor. Figure 2 displays a photograph of the VAWT rotor and the weights mounted upon the rotational axis. An Eiffel-type wind tunnel at Tottori University (square nozzle outlet: $1.5 \mathrm{~m} \times 1.5 \mathrm{~m}$ ) can generate pulsating winds by means of an axial blower that can change its blade angle during constant speed rotation [8]. In the present experiment, a powder brake is manipulated to generate a constant load torque, $T_{L}$. The distance between the wind tunnel outlet and the rotor axis is $1.5 \mathrm{~m}$, and the wind speed, $V$, is measured with a hot wire probe placed at the nozzle outlet.

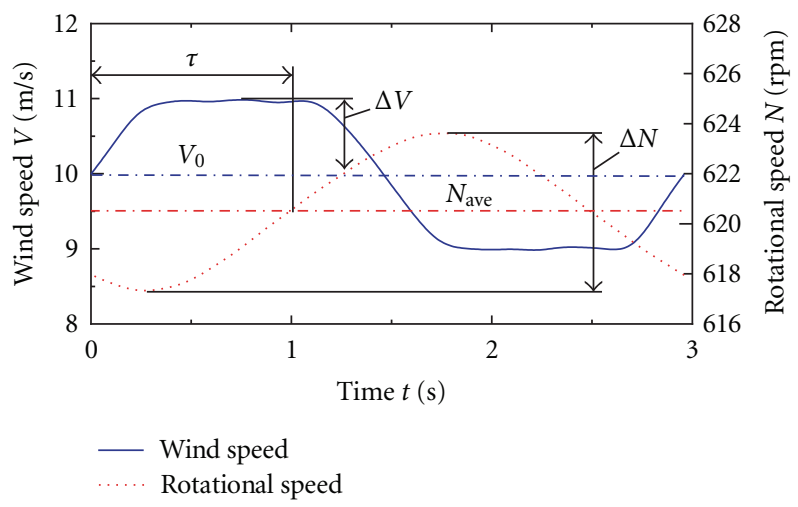

Figure 3: Response of rotational speed to pulsating wind ( $I=$ $\left.0.1 \mathrm{kgm}^{2}, T=3 \mathrm{~s}, \Delta V=1 \mathrm{~m} / \mathrm{s}\right)$.

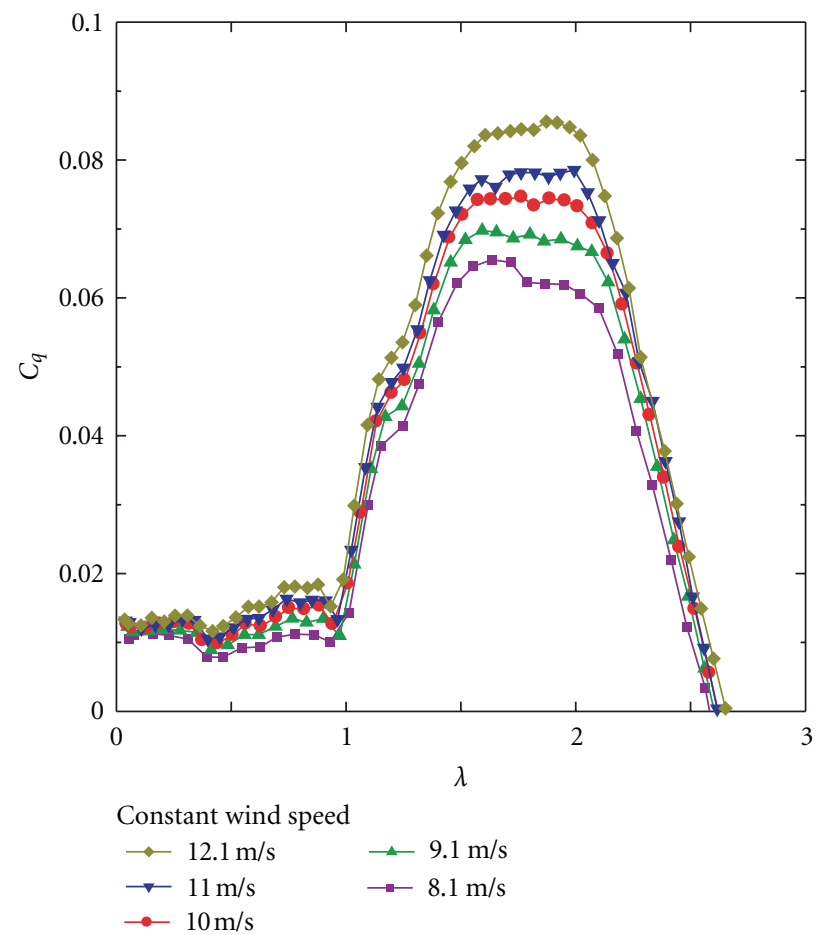

FIgURE 4: Torque coefficients, $C_{q}(\lambda)$, for a VAWT with NACA 0012 airfoils.

\section{Experimental Method}

The mean speed of the pulsating wind was fixed at $V_{0}=$ $10 \mathrm{~m} / \mathrm{s}$, and the amplitude was fixed at $\Delta V=1$ or $2 \mathrm{~m} / \mathrm{s}$. The wind cycle was changed from $T=2$ to $8 \mathrm{~s}$. The load torque was held at around $T_{L}=0.3 \mathrm{Nm}$, consistent with the maximum power condition of the experimental VAWT at $10 \mathrm{~m} / \mathrm{s}$ constant wind speed. The sampling frequency of the rotational and wind speeds was $8 \mathrm{~Hz}$. The recording time for the torque, rotational speed, and wind speed depended on the pulsating wind cycle and was set to between approximately 200 and $250 \mathrm{~s}$. This corresponded to about 50 cycles for $T=4 \mathrm{~s}, 42$ cycles for $T=6 \mathrm{~s}$, and 31 cycles 


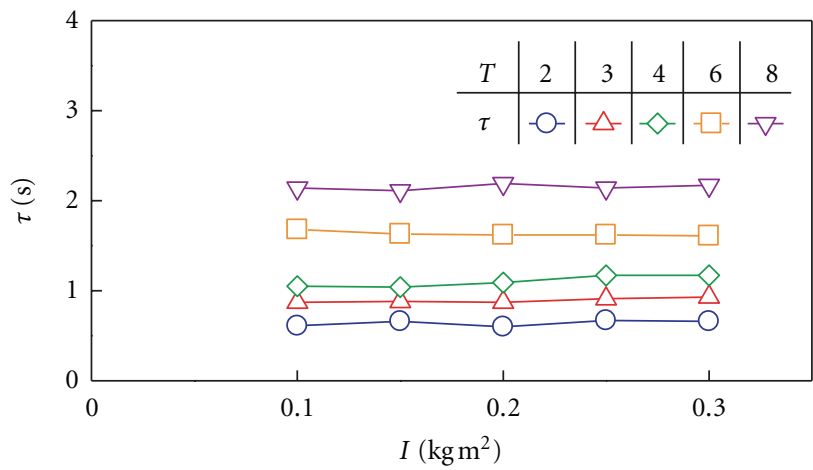

(a)

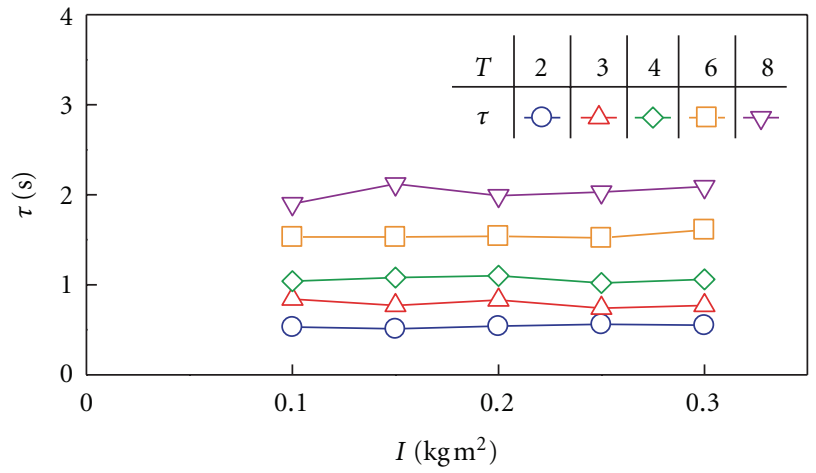

(b)

Figure 5: Time delay, $\tau$, for wind amplitude (a) $\Delta V=1$ and (b) $\Delta V=2 \mathrm{~m} / \mathrm{s}$.

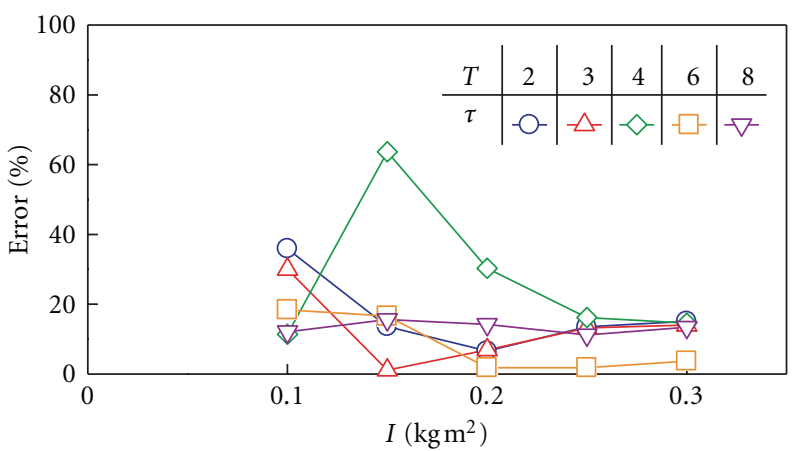

(a)

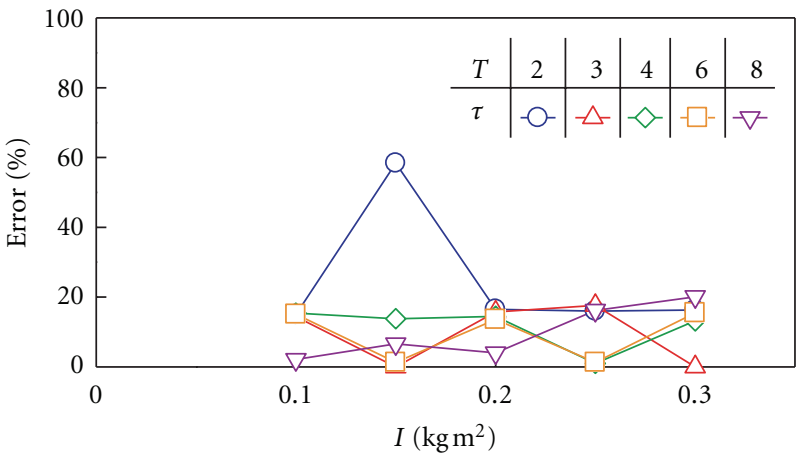

(b)

FiguRE 6: Experimental error of time delay for wind amplitude (a) $\Delta V=1$ and (b) $\Delta V=2 \mathrm{~m} / \mathrm{s}$.

for $T=8 \mathrm{~s}$. All of the measured data were phase-averaged, based on the measured wind speed data, and an example of the averaged data for the wind and rotational speeds is given in Figure 3. Several time series datasets were obtained for each experimental condition, and the output for specific characteristics, such as time delay, was averaged such that a representative value could be found for each condition.

\section{Simulation}

The behavior of angular velocity, $\omega$, in response to the pulsating wind was simulated by using a Runge-Kutta method to numerically integrate the motion equation of the wind turbine:

$$
I \frac{d \omega}{d t}=Q-T_{L}
$$

where

$$
\begin{gathered}
Q=T_{W}-T_{B}, \\
T_{W}=\frac{1}{2} \rho C_{q}(\lambda) V^{2} A R, \\
\lambda=\frac{R \omega}{V} .
\end{gathered}
$$

In (1), $I$ is the moment of inertia for the wind turbine rotor only, and the moments of inertia for the torque detector and powder brake are regarded as insignificant. $Q$ is the effective torque and is defined as the difference between the wind turbine torque, $T_{W}$, and the braking torque, $T_{B}$, coming from the bearings (2). $T_{L}$ is the load torque, which is generated by the powder brake in this case. The wind turbine torque, $T_{W}$, is defined via (3), where $\rho$ is air density.

In the simulation, the torque coefficient $C_{q}(\lambda)$, which is dependent on the tip speed ratio, $\lambda$, and wind speed, $V$, was given by interpolating tabulated data of this coefficient measured under a constant wind speed. Figure 4 presents the torque coefficients of the VAWT used in this study. These torque characteristics were measured without any weights placed upon the rotor axis; however, it was shown that the addition of weights did not result in a significant change to $C_{q}(\lambda)$. Finally, it was assumed that the flow speed at the rotor was the same as the upstream main flow when the latter was set as a sinusoidal wave with an average wind speed of $10 \mathrm{~m} / \mathrm{s}$.

\section{Results and Discussion}

5.1. Time Delay and Rotational Speed Width. An example of the experimental results is shown in Figure 3, where the phase-averaged wind and rotational speeds for about 50 periods are graphically plotted for a case where $\Delta V=1 \mathrm{~m} / \mathrm{s}$, 


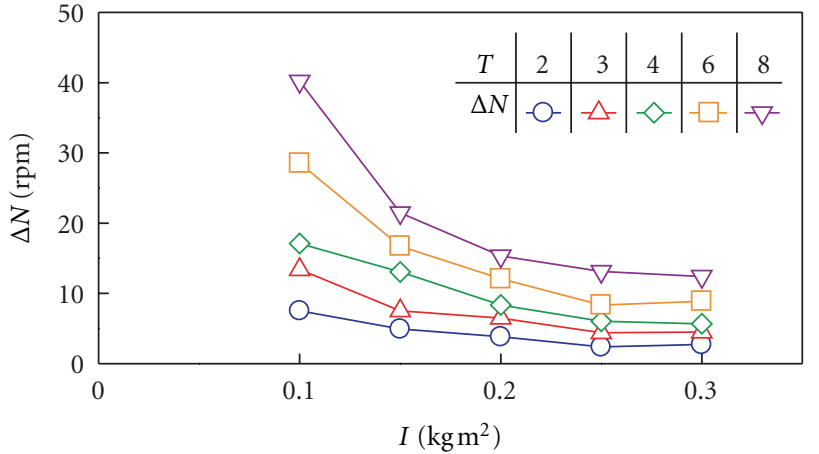

(a)

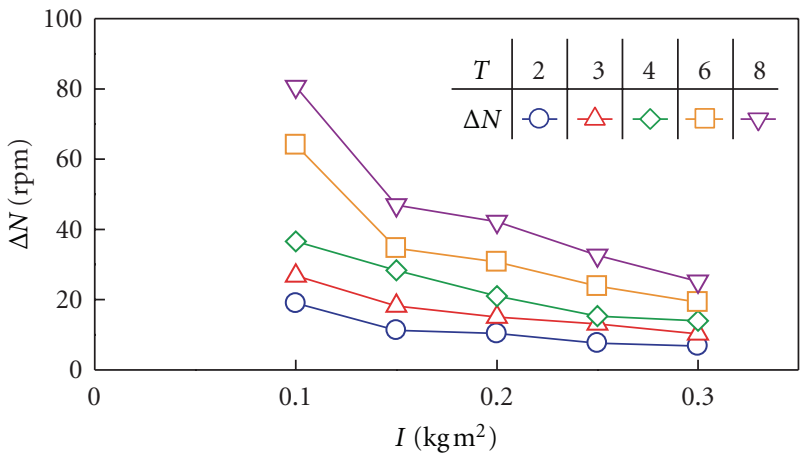

(b)

Figure 7: Rotational speed width, $\Delta N$, for wind amplitude (a) $\Delta V=1$ and (b) $\Delta V=2 \mathrm{~m} / \mathrm{s}$.

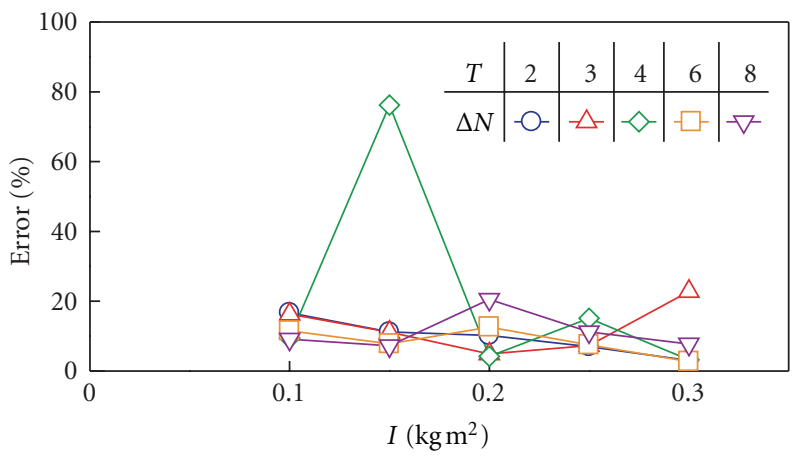

(a)

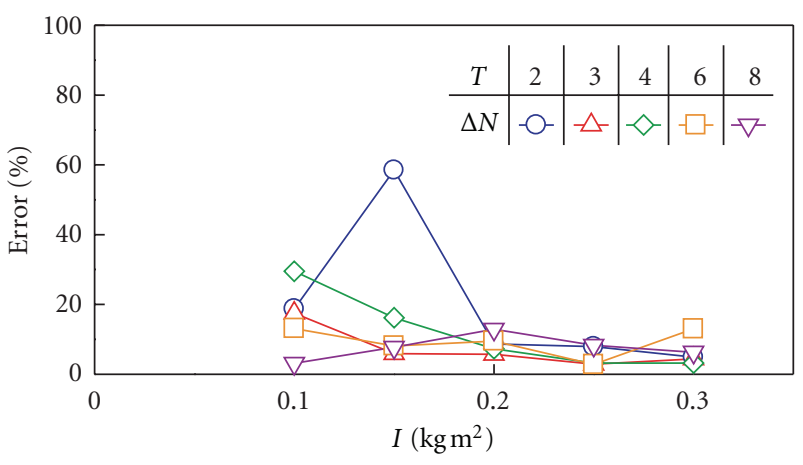

(b)

FIGURE 8: Experimental error of rotational speed width for wind amplitude (a) $\Delta V=1$ and (b) $\Delta V=2 \mathrm{~m} / \mathrm{s}$.

$T=3 \mathrm{~s}$, and $I=0.1 \mathrm{kgm}^{2}$. It can be seen that the rotational speed varies periodically with a constant time-delay, $\tau$, to the wind speed variation. For the case shown in Figure 3, the time-averaged rotational speed is $N_{\text {ave }}=620.5 \mathrm{rpm}$, and the rotational speed width $(p-p)$ is $\Delta N=6.3 \mathrm{rpm}$.

The data in Figure 5(a) are the time delays for the case where $\Delta V=1 \mathrm{~m} / \mathrm{s}$. These delays were corrected by uniformly subtracting $0.15 \mathrm{~s}$ to account for the wind speed being measured $1.5 \mathrm{~m}$ upstream from the rotor center. Additionally, the delay in the wind variation resulting from the axial distance was measured for the unsteady wind generated by the wind tunnel described in Section 2 [9]. Figure 5(a) shows that the time delay increases with the wind cycle, but stays constant for increases in the moment of inertia. The time delays show a similar dependence on the wind cycle, $T$, and the moment of inertia, $I$, for the case when $\Delta V=2 \mathrm{~m} / \mathrm{s}$ in Figure 5(b).

The experimental error for the time delays, $\tau(s)$, measured under each experimental condition, is shown in Figures 6(a) and 6(b). The experimental error is defined as the difference between the maximum and the minimum values found for the 3-5 measurements of $\tau$ expressed as a percentage of the average value of the measurements. The experimental errors were $15.8 \%$ when $\Delta V=1 \mathrm{~m} / \mathrm{s}$ and $12.9 \%$ when $\Delta V=2 \mathrm{~m} / \mathrm{s}$.

The dependence of the rotational speed width, $\Delta N$, on both the moment of inertia and wind cycle, for $\Delta V=1 \mathrm{~m} / \mathrm{s}$, is given in Figure 7(a) and shows that the speed width, $\Delta N$, increases with wind cycle, $T$, and decreases with the moment of inertia, $I$. When $\Delta V=2 \mathrm{~m} / \mathrm{s}$, the dependence of $\Delta N$ on $T$ and $I$ is nearly identical to that when $\Delta V=1 \mathrm{~m} / \mathrm{s}$, although the values of $\Delta N$ are almost double (Figure $7(\mathrm{~b})$ ). As above, the experimental error for the rotational speed width, $\Delta N$ $(\mathrm{rpm})$, measured for each experimental condition, are shown in Figures $8(\mathrm{a})$ and $8(\mathrm{~b})$, and the experimental errors for $\Delta N$ are $12.6 \%$ when $\Delta V=1 \mathrm{~m} / \mathrm{s}$ and $11.2 \%$ when $\Delta V=2 \mathrm{~m} / \mathrm{s}$.

5.2. Phase Delay. Phase delays, $\phi(=\tau / T \times 2 \pi)$, between the rotational speed variation and wind variation are displayed in Figures 9(a) and 9(b), for the cases where $\Delta V=1 \mathrm{~m} / \mathrm{s}$ and $\Delta V=2 \mathrm{~m} / \mathrm{s}$, respectively. For the former, the phase delay is increased for short wind cycles, $T$. Conversely, when $\Delta V=$ $2 \mathrm{~m} / \mathrm{s}$, the phase delay remains nearly constant throughout. The average simulated phase delay, represented by the broken line in Figure 9, is found to be approximately $\pi / 2$ in both cases.

5.3. Rate of Change of Rotational Speed. The rate of change of the rotational speed divided by the wind cycle, $\left(\Delta N / N_{\mathrm{ave}}\right) / T$, is shown for both wind amplitudes in Figures 10(a) and 10 (b). For each $\Delta V$ case, the values of $\left(\Delta N / N_{\text {ave }}\right) / T$ are expressed by a curve inversely proportional to the moment of inertia, $I$, and independent of the wind cycle, T. For 


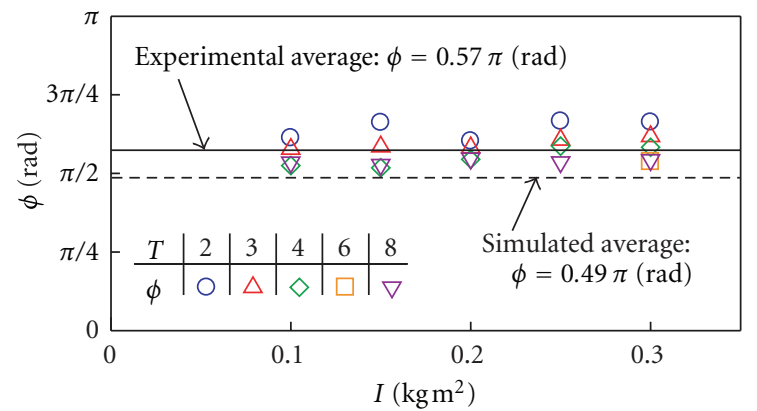

(a)

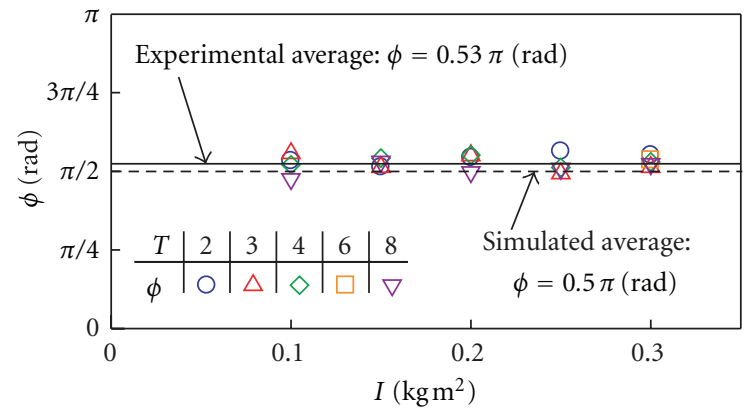

(b)

Figure 9: Phase delay, $\phi$, for wind amplitude (a) $\Delta \mathrm{V}=1$ and (b) $\Delta \mathrm{V}=2 \mathrm{~m} / \mathrm{s}$.

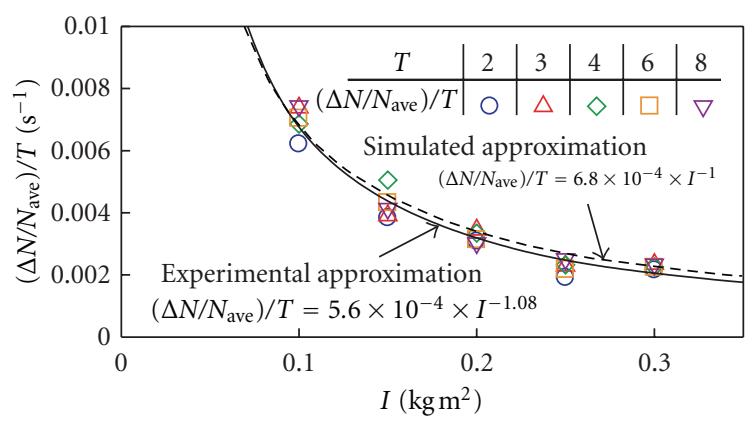

(a)

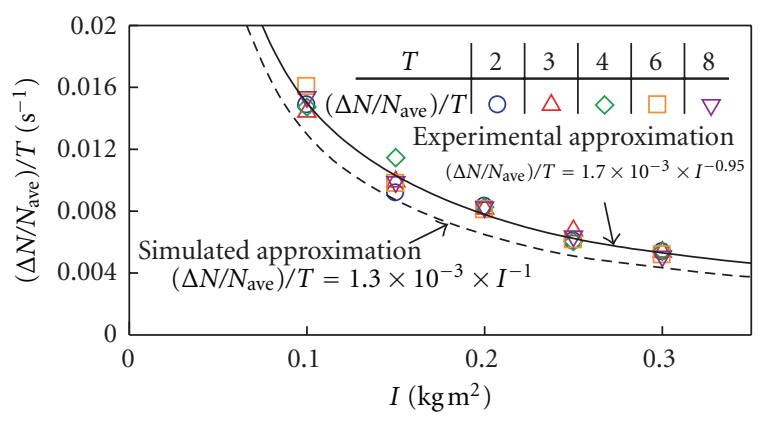

(b)

Figure 10: Rate of change of rotational speed divided by wind cycle, $\left(\Delta N / N_{\text {ave }}\right) / T$, for wind amplitude (a) $\Delta V=1$ and (b) $\Delta V=2 \mathrm{~m} / \mathrm{s}$.

$\Delta V=2 \mathrm{~m} / \mathrm{s}$, a difference exists between the experimental results and those from the simulation depicted by the broken curve. Nevertheless, for both cases of $\Delta V$, the experimental and simulated outputs largely conform to each other.

Comparing coefficients of the two simulated curves, the coefficient when $\Delta V=2 \mathrm{~m} / \mathrm{s}$ is around twice as large as that for $\Delta V=1 \mathrm{~m} / \mathrm{s}$. Therefore, the rotational speed width may be expressed by

$$
\Delta N \approx C\left(\frac{N_{\text {ave }}}{I}\right) T \Delta V
$$

where $C$ is a constant and takes a value of around $6.8 \times 10^{-4}$ for the wind turbine used here.

5.4. Energy Efficiency. The experimental energy efficiency, $\eta(\%)$, of the wind turbine is shown in Figures 11(a) and 11(b), together with simulated results depicted by broken lines. Figure 12 presents the experimental error of $\eta$ for each experimental condition. For the case when $\Delta V=1 \mathrm{~m} / \mathrm{s}$, the experimental energy efficiency error is $4.0 \%$, and when $\Delta V$ $=2 \mathrm{~m} / \mathrm{s}$, the error is $5.1 \%$. In this study, $\eta$ is defined as the ratio between the mechanical power, $P_{T}$, of the turbine and the input wind power, $P_{W}$, expressed as a percentage:

$$
\eta=100\left(\frac{P_{T}}{P_{W}}\right)
$$

where

$$
\begin{gathered}
P_{T}=\frac{1}{T} \sum_{0}^{T} \omega T_{L} \Delta t, \\
P_{W}=\frac{1}{T} \sum_{0}^{T} \frac{1}{2} \rho A V^{3} \Delta t .
\end{gathered}
$$

In (7), $\Delta t$ is the data sampling time interval and $\sum$ indicates summation over a wind cycle.

From Figures 11(a) and 11(b), the energy efficiency tends to decrease with increasing moment of inertia, $I$. However, this tendency was caused by an increase in the braking torque of the bearings, which affected by the weights added to change the moment of inertia. For both cases of $\Delta V$, the simulated energy efficiency is not dependent on $I$ or $T$, but the energy efficiency does decrease when the wind amplitude is large. This decrease in efficiency results from the fact that, although raising the wind amplitude leads to increased input energy, the average power of the wind turbine remains unchanged, or even decreases slightly, when the wind amplitude is altered. Figure 13 shows the loci of the simulated mechanical power, $P_{T}$, for the wind turbine, in the case $T=4 \mathrm{~s}$. The average powers $(20.6 \mathrm{~W}$ for $\Delta V=1 \mathrm{~m} / \mathrm{s}$, $19.8 \mathrm{~W}$ for $\Delta V=2 \mathrm{~m} / \mathrm{s}$ ) are almost the same, regardless of $\Delta V$, whereas the input wind power, $P_{W}$, increases by $4.7 \%$ when $\Delta V$ is doubled $(171 \mathrm{~W}$ for $\Delta V=1 \mathrm{~m} / \mathrm{s}, 179 \mathrm{~W}$ for $\Delta V$ $=2 \mathrm{~m} / \mathrm{s}$ ). 


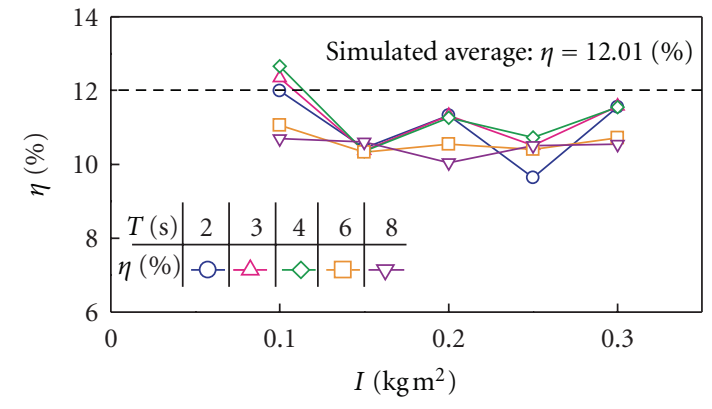

(a)

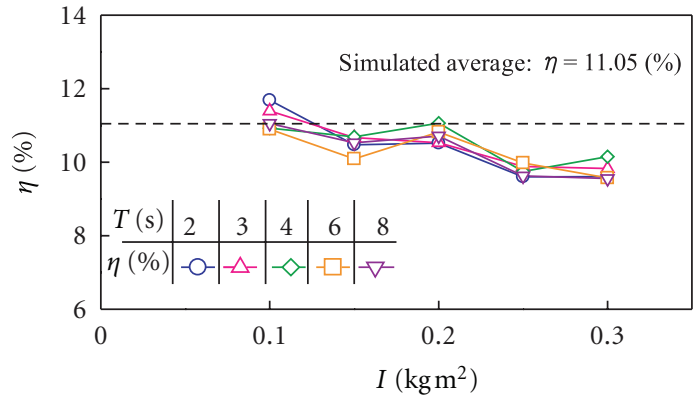

(b)

FIgURE 11: Energy efficiency, $\eta$, for wind amplitude (a) $\Delta V=1$ and (b) $\Delta V=2 \mathrm{~m} / \mathrm{s}$.

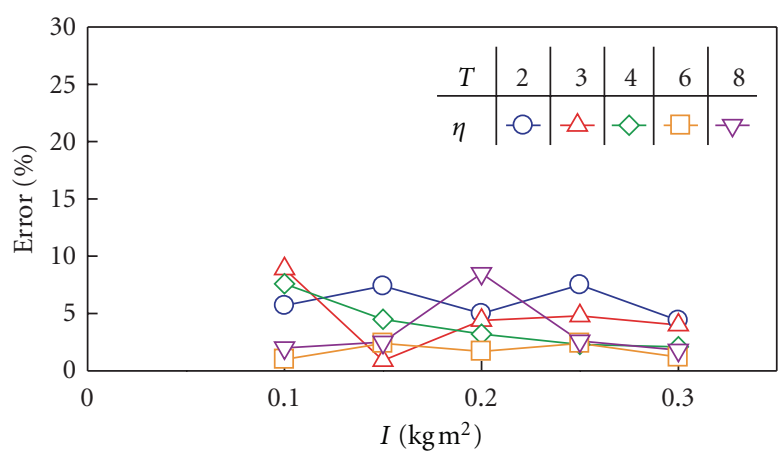

(a)

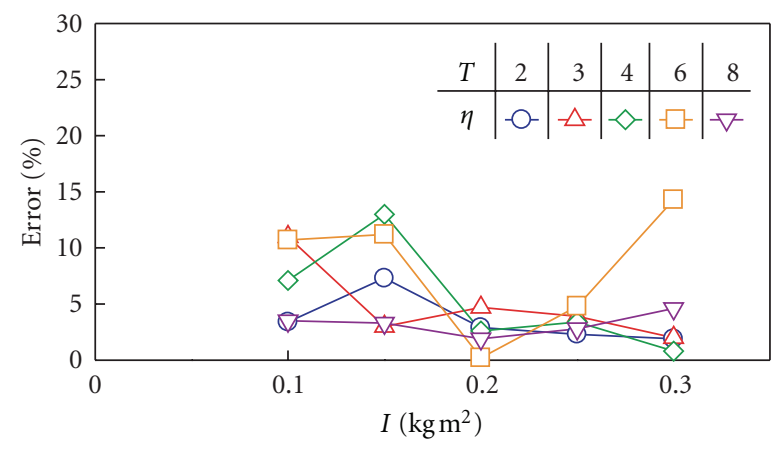

(b)

FIgURE 12: Experimental error of energy efficiency for wind amplitude (a) $\Delta V=1$ and (b) $\Delta V=2 \mathrm{~m} / \mathrm{s}$.

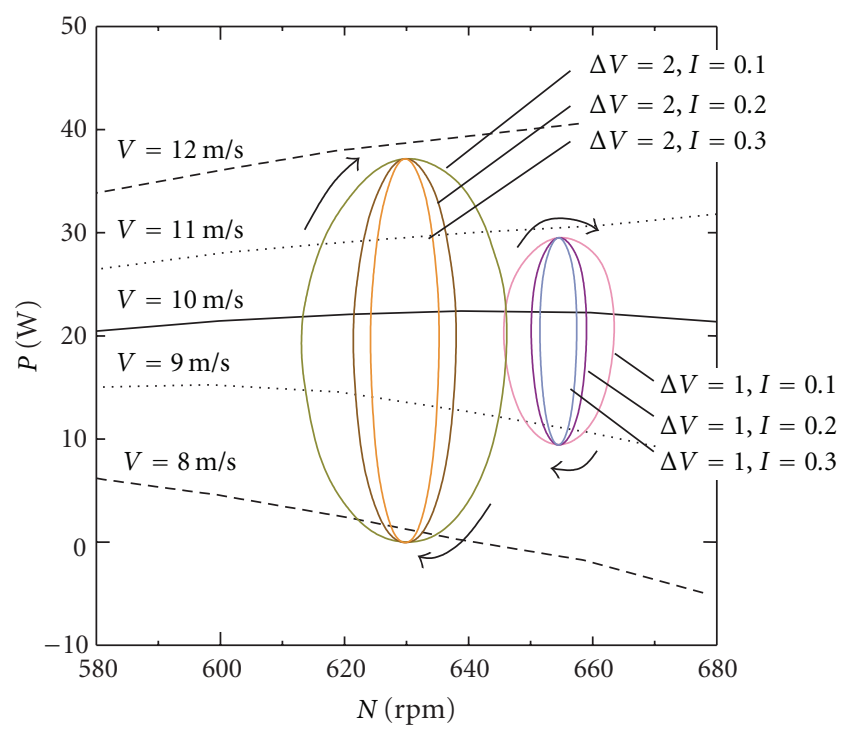

FIGURE 13: Loci of simulated mechanical power of the wind turbine in the case $T=4 \mathrm{~s}$. (Note: power curves of the wind turbine measured at five wind speeds from $8-12 \mathrm{~m} / \mathrm{s}$ are also shown.)

\section{Numerical Analysis of a Theoretical VAWT}

In the previous section, numerical simulations showed good agreement with experimental results. In this section, similar simulations are reported for a theoretical VAWT of different size with different airfoils. This new VAWT has four straight blades with NACA 0018 airfoils $(c=0.15 \mathrm{~m}), D=2 \mathrm{~m}$, and $H=1.5 \mathrm{~m}$. The swept area $\left(A=3 \mathrm{~m}^{2}\right)$ is about 10 -fold that of the experiment rotor $\left(0.282 \mathrm{~m}^{2}\right)$. I of the new VAWT is estimated to be about $5 \mathrm{kgm}^{2}$ if the blades are made of a lightweight material with a density of $300 \mathrm{~kg} / \mathrm{m}^{3}$. Power and torque were calculated by using blade element momentum theory $[1,10-12]$. Simulated power $\left(C_{p}\right)$ and torque $\left(C_{q}\right)$ coefficients are presented in Figure 14 for nine wind speeds from 6 to $14 \mathrm{~m} / \mathrm{s}$. In these performance calculations, the double-multiple streamtube model was used for flow field modeling and the modified Gormont model [1] was applied to consider the effect of dynamic stall. The parameter $A_{M}$ in the dynamic stall model was set to 1000 in this study. Aerodynamic data (lift coefficient, $C_{L}$, and drag coefficient, $C_{D}$ ) needed for the performance calculation were taken from [13] for $R_{e}=1.0 \times 10^{4}-1.6 \times 10^{5}$ and from [14] for $R_{e}>1.6 \times 10^{5}$. Two peaks appear in the $C_{q}-\lambda$ curves at each constant wind speed in Figure 14(b). The right-hand peak corresponds to the maximum torque based on the static aerodynamic data, and the left-hand peak is attributed to the dynamic stall effects.

To simulate the response of the theoretical VAWT, the amplitude of the pulsating wind was fixed at $\Delta V=1 \mathrm{~m} / \mathrm{s}$ only, whereas the mean speed of the pulsating wind was fixed at $V_{0}=7,10$, and $13 \mathrm{~m} / \mathrm{s}$, and the wind cycle at $T=$ $4,8,16$, and $32 \mathrm{~s}$. Simulations were performed following the method described in Section 4, and (1) was numerically 


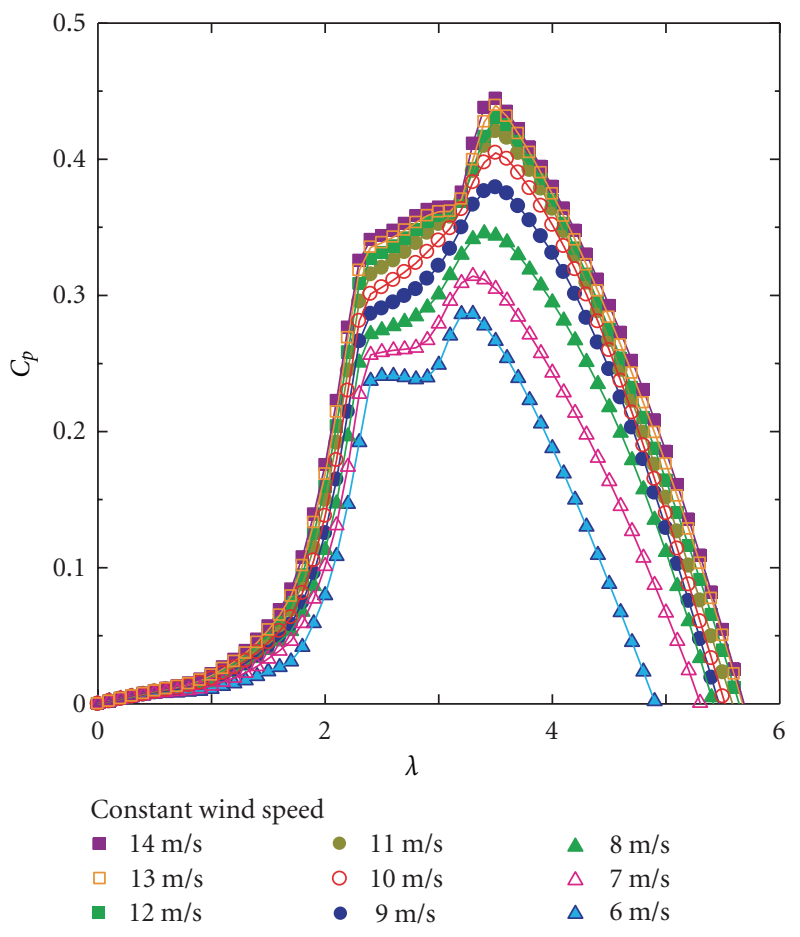

(a)

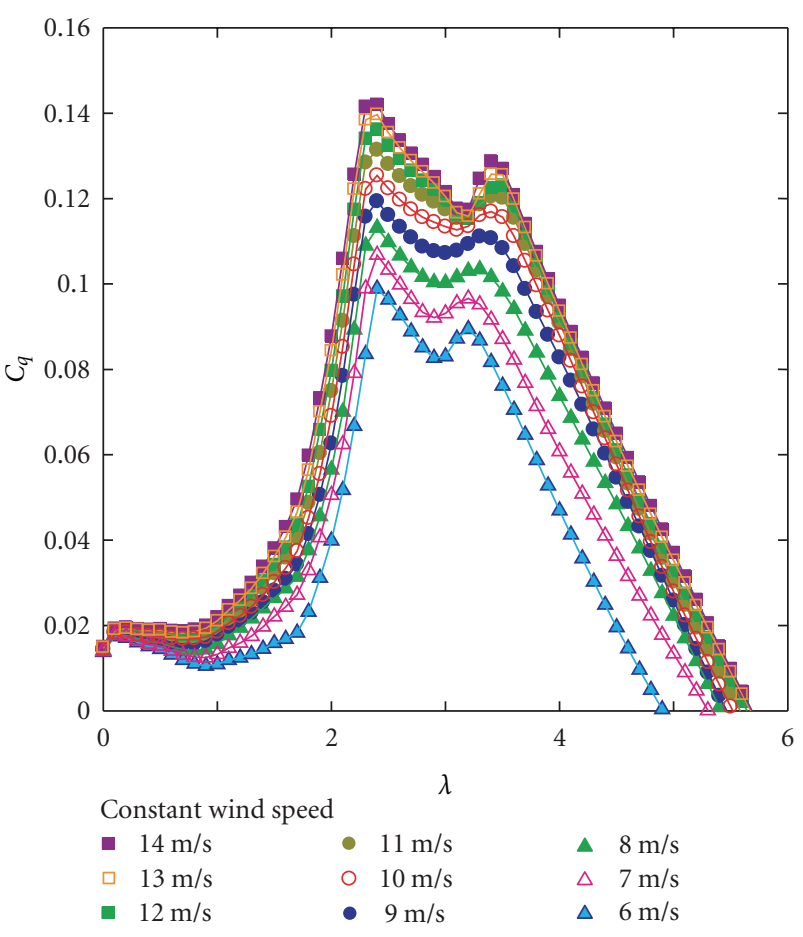

(b)

FIgURE 14: Simulated power $\left(C_{p}\right)$ and torque $\left(C_{q}\right)$ coefficients for a theoretical VAWT with NACA 0018 airfoil.

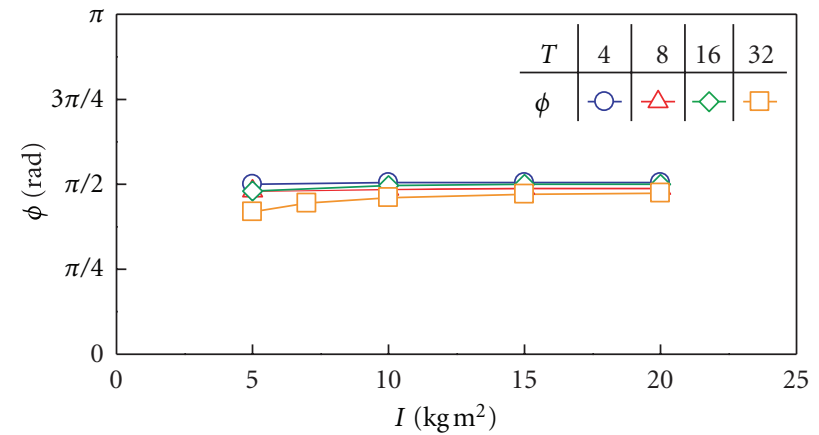

(a)

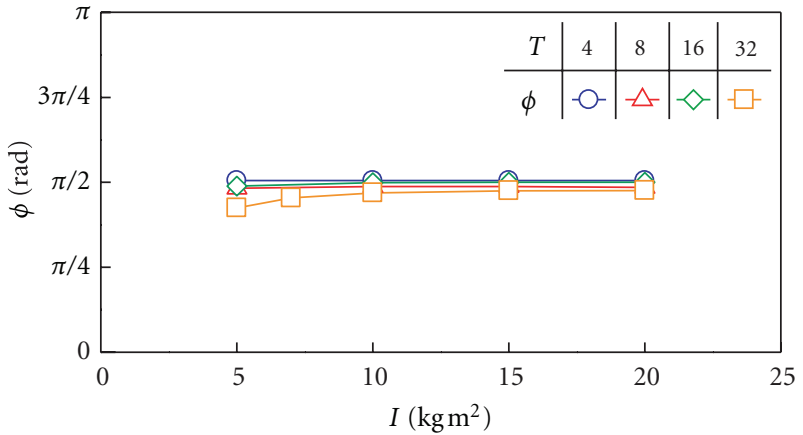

(b)

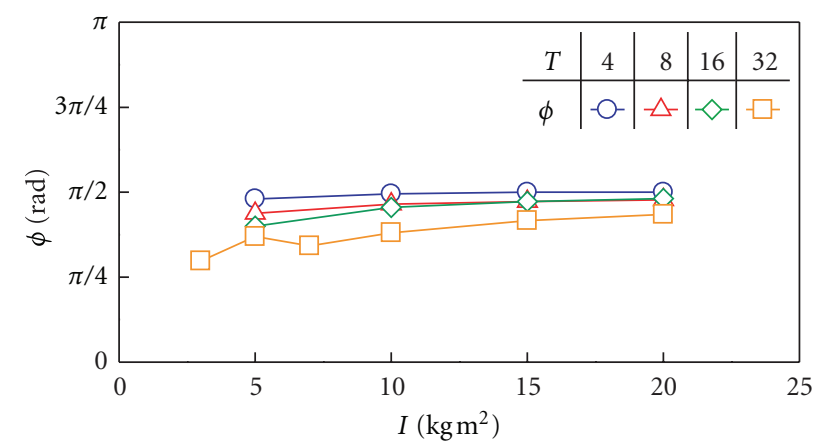

(c)

Figure 15: Phase delay, $\phi$, for mean wind speed (a) $V_{0}=7$, (b) $V_{0}=10$, and (c) $V_{0}=13 \mathrm{~m} / \mathrm{s}$. 


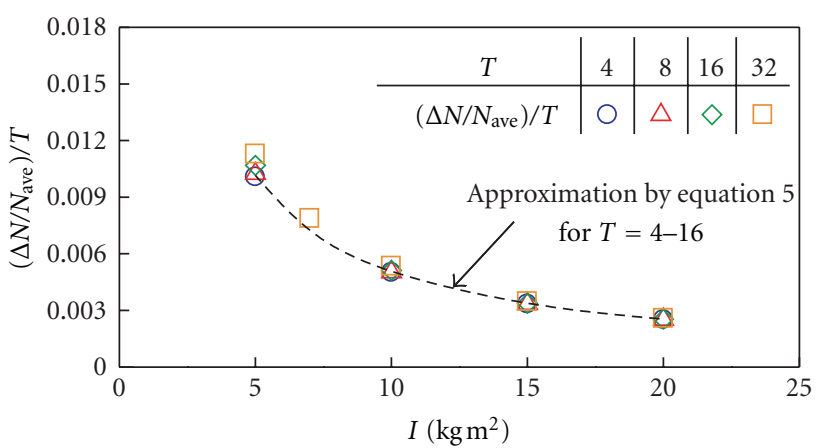

(a)

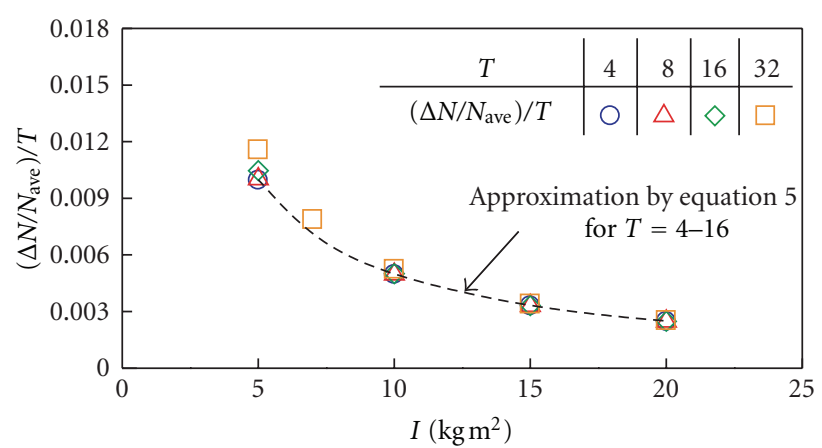

(b)

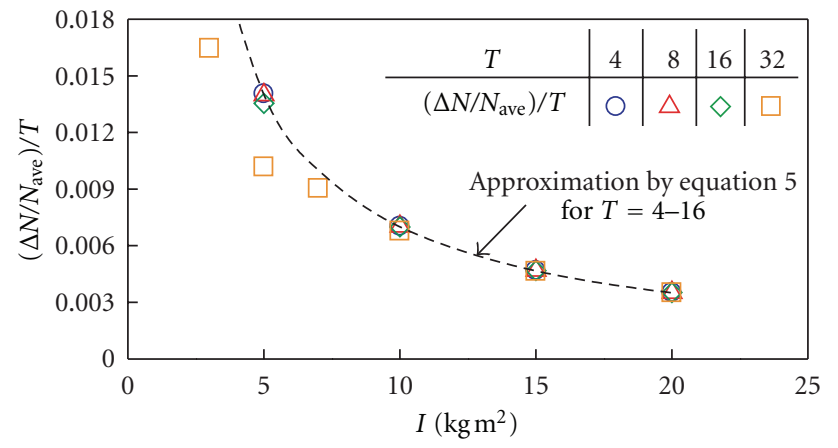

(c)

FIGURE 16: Rate of change of rotational speed divided by wind cycle, $\left(\Delta N / N_{\text {ave }}\right) / T$, for mean wind speed (a) $V_{0}=7$, (b) $V_{0}=10$, and $(\mathrm{c}) V_{0}=$ $13 \mathrm{~m} / \mathrm{s}$.

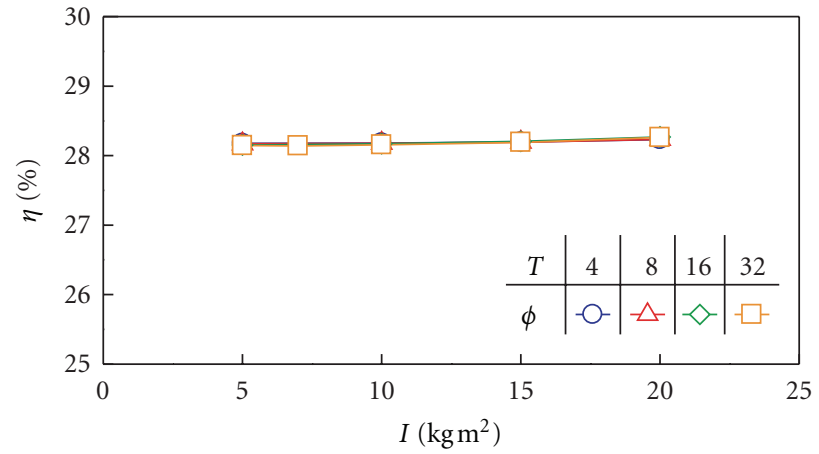

(a)

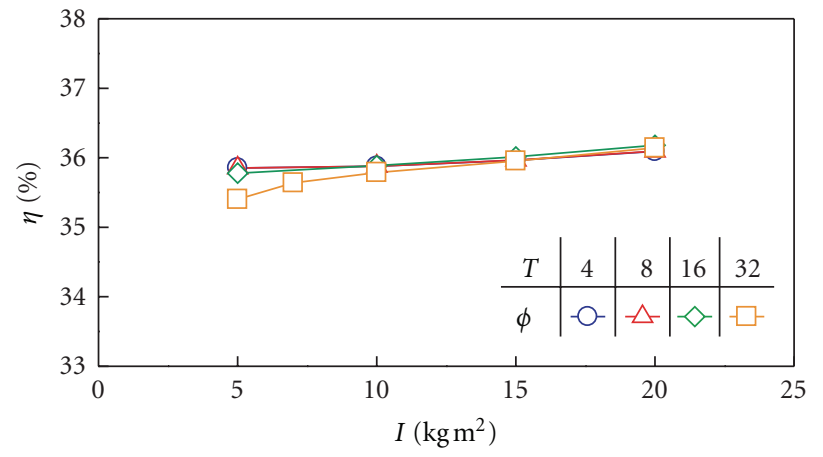

(b)

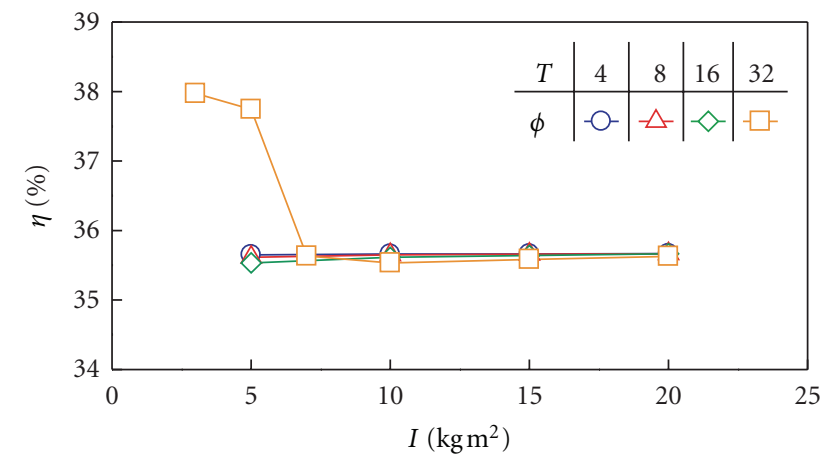

(c)

Figure 17: Energy efficiency, $\eta$, for mean wind speed (a) $V_{0}=7$, (b) $V_{0}=10$, and (c) $V_{0}=13 \mathrm{~m} / \mathrm{s}$. 


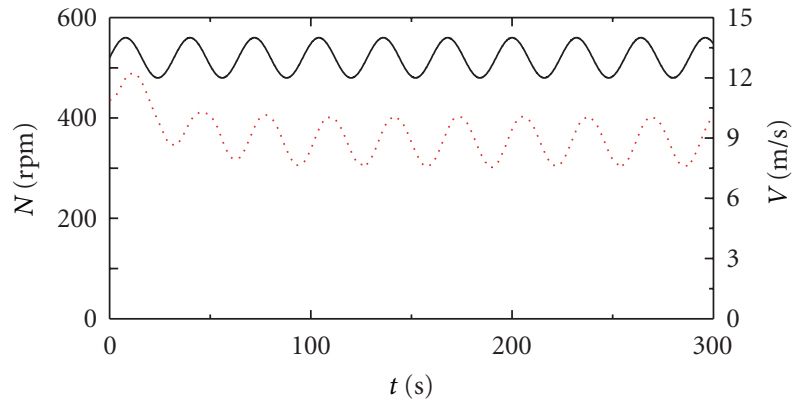

Rotation

— Wind

FIGURE 18: Time profile of the rotational speed of pulsating wind in the case where $V_{0}=13 \mathrm{~m} / \mathrm{s}, T=32 \mathrm{~s}$, and $I=7 \mathrm{kgm}^{2}$.

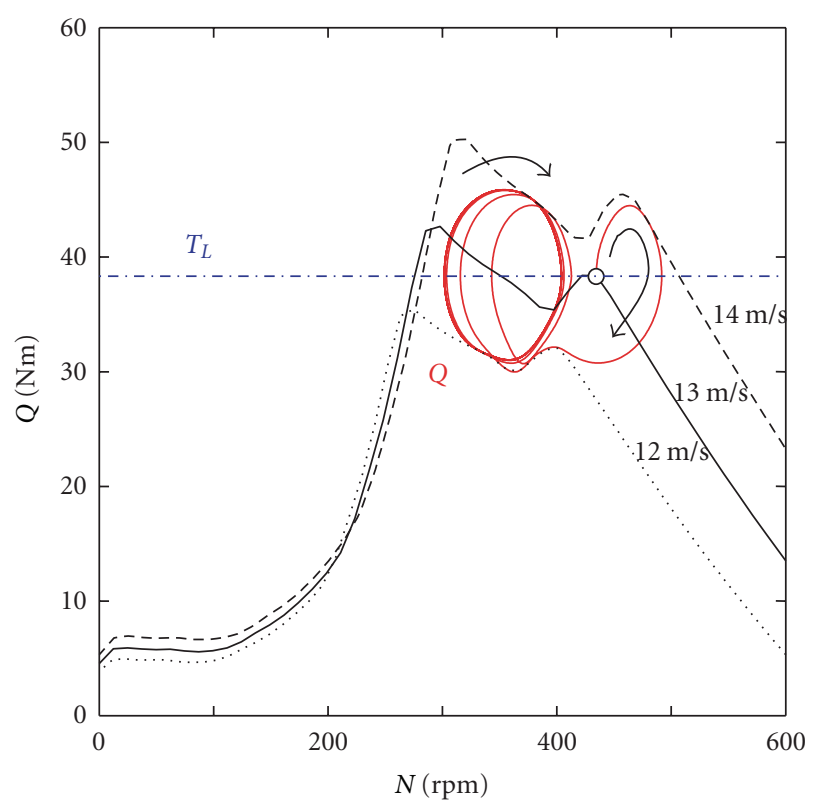

O Initial state

Figure 19: Locus of torque, $Q$, of pulsating wind in the case where $V_{0}=13 \mathrm{~m} / \mathrm{s}, T=32 \mathrm{~s}$, and $I=7 \mathrm{kgm}^{2}$. Constant load torque is $T_{L}=$ $38.3 \mathrm{Nm}$. Final average rotational speed is $N_{\mathrm{ave}}=353.9 \mathrm{rpm}$.

integrated from an initial state, which was taken to be the maximum power state of the rotor at the mean wind speed. The calculation time was $300 \mathrm{~s}$ for a time interval of $0.01 \mathrm{~s}$, and the steady-state data between 200 and $300 \mathrm{~s}$ were used in the analysis. Three torque curves were input as data into the simulation. For example, when $V_{0}=7 \mathrm{~m} / \mathrm{s}$, the torque coefficients, $C_{q}(\lambda)$, for $V=6,7$, and $8 \mathrm{~m} / \mathrm{s}$ shown in Figure 14 were used. Furthermore, for the simulations in this section, the braking torque, $T_{B}$, was ignored $\left(T_{B}=0\right.$; i.e., $\left.Q=T_{W}\right)$.

Phase delays, $\phi=(\tau / T \times 2 \pi)$, at each mean wind speed are displayed in Figure 15. In cases where $V_{0}=7$ or $10 \mathrm{~m} / \mathrm{s}$ and $T=4,8$, or $16 \mathrm{~s}$ all phase delays are approximately $\pi / 2$. However, when $V_{0}=7$ or $10 \mathrm{~m} / \mathrm{s}$ and $T=32 \mathrm{~s}$, the phase delay is less than $\pi / 2$ when the moment of inertia is small

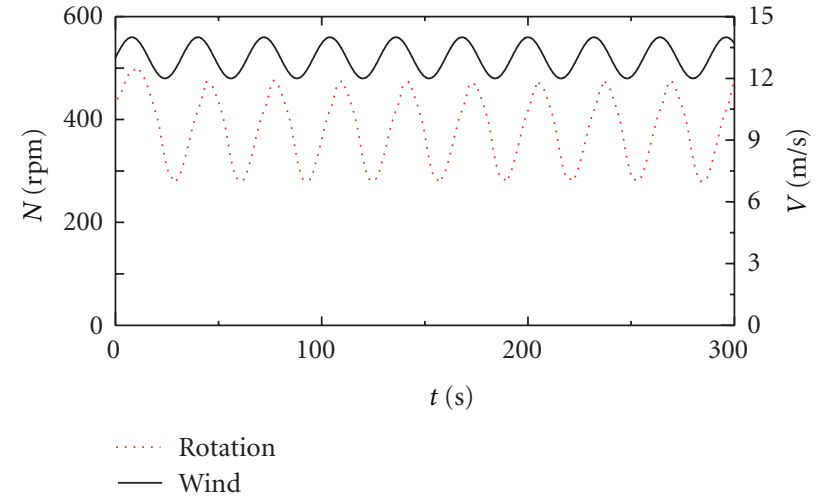

FIGURE 20: Time profile of rotational speed of pulsating wind in the case where $V_{0}=13 \mathrm{~m} / \mathrm{s}, T=32 \mathrm{~s}$, and $I=3 \mathrm{kgm}^{2}$.

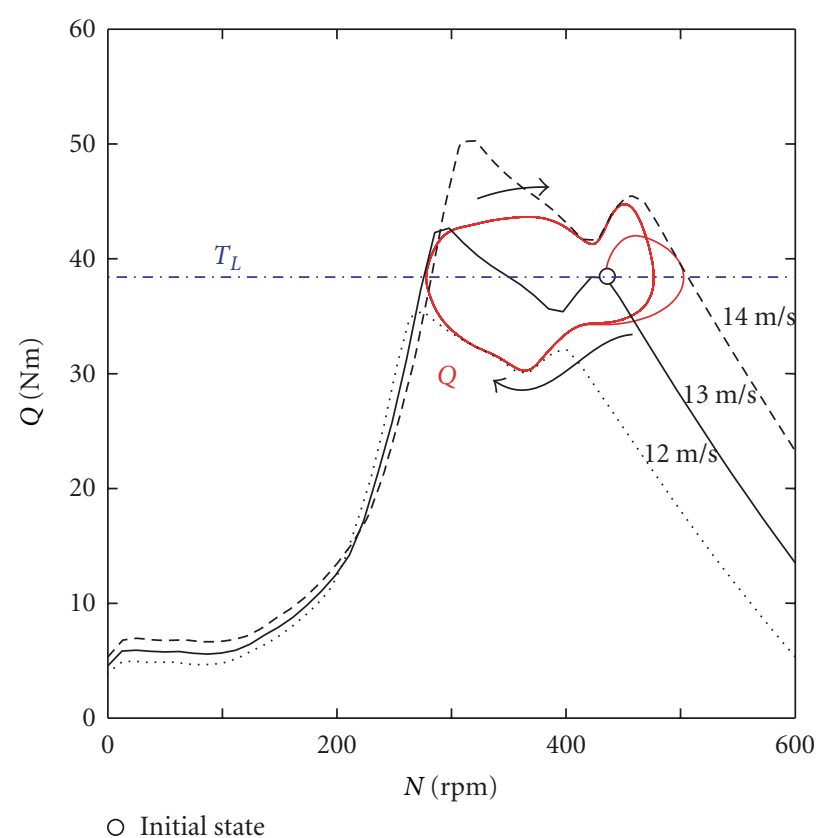

Figure 21: Locus of torque, $Q$, of pulsating wind in the case where $V_{0}=13 \mathrm{~m} / \mathrm{s}, T=32 \mathrm{~s}$, and $I=3 \mathrm{kgm}^{2}$. Constant load torque is $T_{L}=$ $38.3 \mathrm{Nm}$. Final average rotational speed is $N_{\text {ave }}=377.1 \mathrm{rpm}$.

$\left(I=5\right.$ or $\left.7 \mathrm{kgm}^{2}\right)$. When the mean wind speed is large $\left(V_{0}=\right.$ $13 \mathrm{~m} / \mathrm{s}$ ), this tendency becomes more remarkable.

Dependence of $\left(\Delta N / N_{\text {ave }}\right) / T$ on $I$ is shown for each mean wind speed in Figure 16. At all mean wind speeds, when $T=4,8$, or $16 \mathrm{~s}$, the values of $\left(\Delta N / N_{\text {ave }}\right) / T$ are independent of $T$ and match well with the approximation in (5). The curve constants $C$ of the theoretical VAWT are $0.0508,0.0499$, and 0.0700 for $V_{0}=7,10$, and $13 \mathrm{~m} / \mathrm{s}$, respectively. Roughly speaking, the $C$ increases in accordance with the order of the moment of inertia $\left(C=6.8 \times 10^{-4}\right.$ for $I=0.1 \mathrm{kgm}^{2}$ of the experimental rotor; $C \approx 5.0 \times 10^{-2}$ for $I \approx 5 \mathrm{kgm}^{2}$ of the theoretical rotor). However, for a fixed rotor size and shape, the value of $C$ shows a weak dependence on the mean speed of the pulsating wind. For $T=32 \mathrm{~s}$ in Figure 16, the values of $\left(\Delta N / N_{\text {ave }}\right) / T$ tend to diverge from approximations given by 


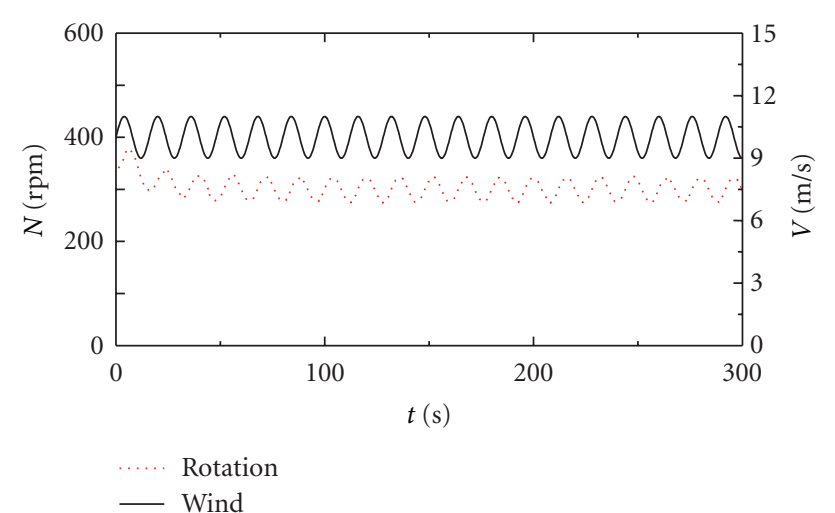

FIGURE 22: Time profile of rotational speed of pulsating wind in the case where $V_{0}=10 \mathrm{~m} / \mathrm{s}, T=16 \mathrm{~s}$, and $I=5 \mathrm{kgm}^{2}$.

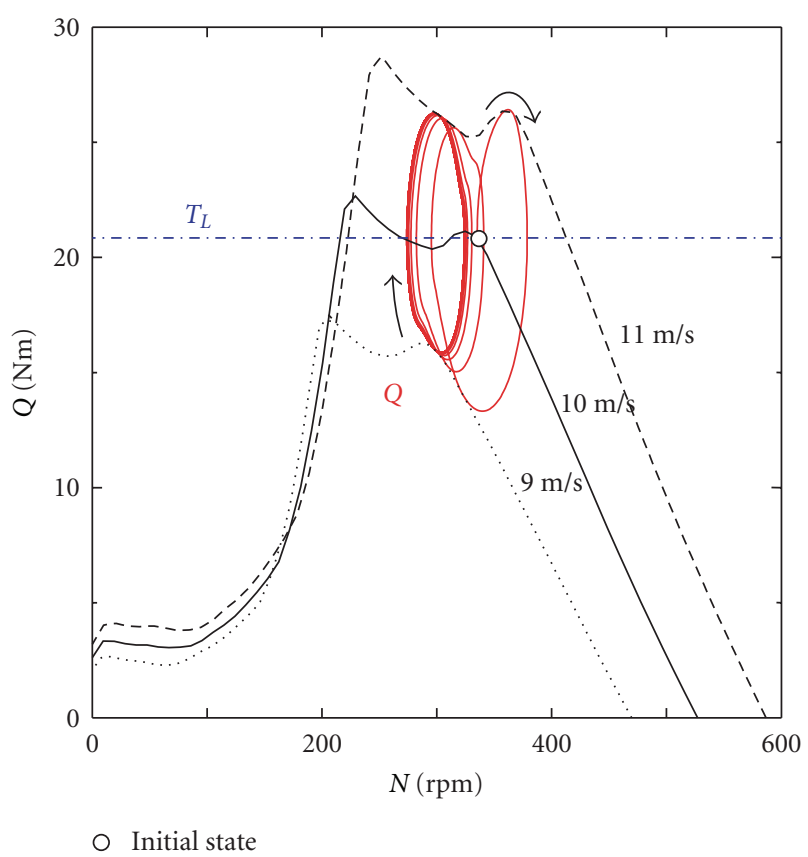

Figure 23: Locus of torque, $Q$, of pulsating wind in the case where $V_{0}=10 \mathrm{~m} / \mathrm{s}, T=16 \mathrm{~s}$, and $I=5 \mathrm{kgm}^{2}$. Constant load torque is $T_{L}=$ $20.8 \mathrm{Nm}$. Final average rotational speed is $N_{\mathrm{ave}}=299.4 \mathrm{rpm}$.

(5) when $I<10 \mathrm{kgm}^{2}$. However, the divergence of the large wind speed case is different than those for small and medium wind speeds.

Energy efficiencies, $\eta(\%)$, are shown in Figure 17. The efficiency reflects the effect of the Reynolds number on the blade aerodynamic performance and $\eta \approx 28 \%$ when $V_{0}=$ $7 \mathrm{~m} / \mathrm{s}$, and $\eta \approx 36 \%$ when $V_{0}=10$ or $13 \mathrm{~m} / \mathrm{s}$. At all mean wind speeds, when $T=4,8$, or $16 \mathrm{~s}, \eta$ is almost independent of both $T$ and $I$. However, in the case $T=32 \mathrm{~s}$, efficiency varies when $I$ is small. Moreover, for $V_{0}=10 \mathrm{~m} / \mathrm{s}, \eta$ decreases with decreasing moment of inertia. In contrast, when $V_{0}=$ $13 \mathrm{~m} / \mathrm{s}, \eta$ increases abruptly when $I<7 \mathrm{kgm}^{2}$.

To elucidate the above-mentioned behavior of the energy efficiency when $T$ is large and $I$ is small, time profiles of the

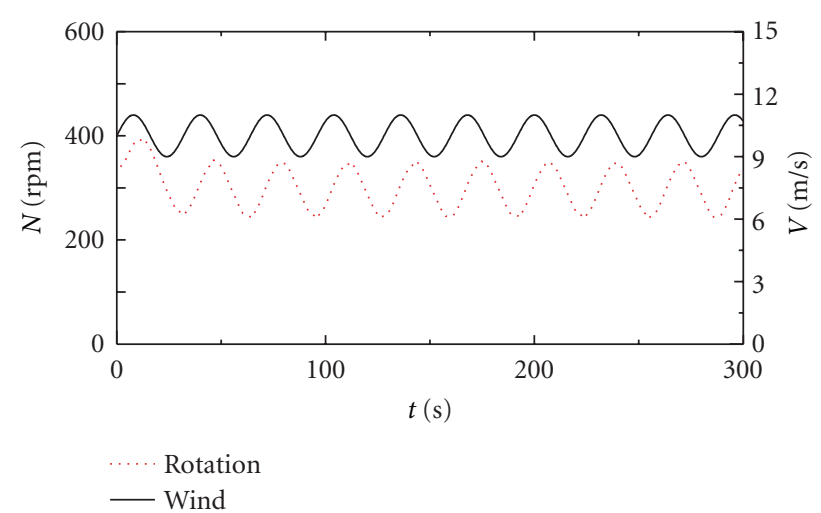

FIGURE 24: Time profile of rotational speed of pulsating wind in the case where $V_{0}=10 \mathrm{~m} / \mathrm{s}, T=32 \mathrm{~s}$, and $I=5 \mathrm{kgm}^{2}$.

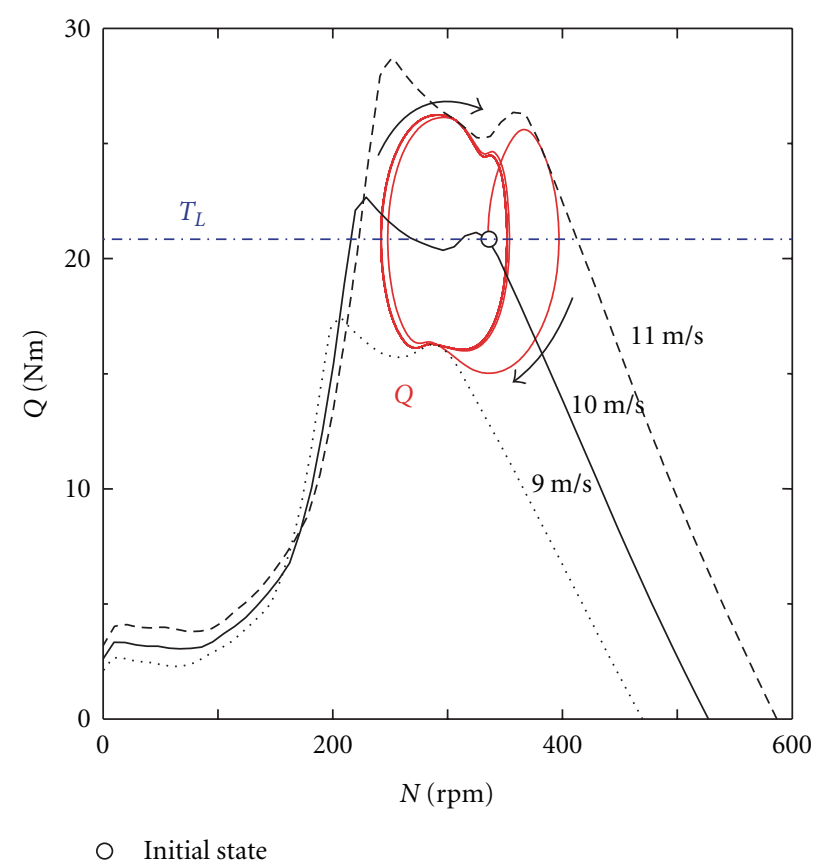

FIGURE 25: Locus of torque, $Q$, of pulsating wind in the case where $V_{0}=10 \mathrm{~m} / \mathrm{s}, T=32 \mathrm{~s}, I=5 \mathrm{kgm}^{2}$. Constant load torque is $T_{L}=$ $20.8 \mathrm{Nm}$. Final average rotational speed is $N_{\mathrm{ave}}=296.2 \mathrm{rpm}$.

rotational speed, $N$, and the loci of the effective torque, $Q$, are next presented. The initial state of each profile and locus is the maximum power state of the mean wind speed.

For the case where $V_{0}=13 \mathrm{~m} / \mathrm{s}, T=32 \mathrm{~s}$, and $I=$ $7 \mathrm{kgm}^{2}$, the time profile of $N$ is shown in Figure 18 and the corresponding locus of $Q$ is presented in Figure 19. Similarly, for the case where $V_{0}=13 \mathrm{~m} / \mathrm{s}, T=32 \mathrm{~s}$, and $I=3 \mathrm{kgm}^{2}$, the time profile and locus are shown in Figures 20 and 21, respectively. Comparing the cases where $I=7 \mathrm{kgm}^{2}$ (Figures 18 and 19) and $I=3 \mathrm{kgm}^{2}$ (Figures 20 and 21), a rapid change in the rotational speed due to the small moment of inertia $\left(I=3 \mathrm{kgm}^{2}\right)$ causes increases in the rotational speed width, $\Delta N$, the average rotational speed, $N_{\text {ave }}\left(N_{\text {ave }}=353.9\right.$ and 


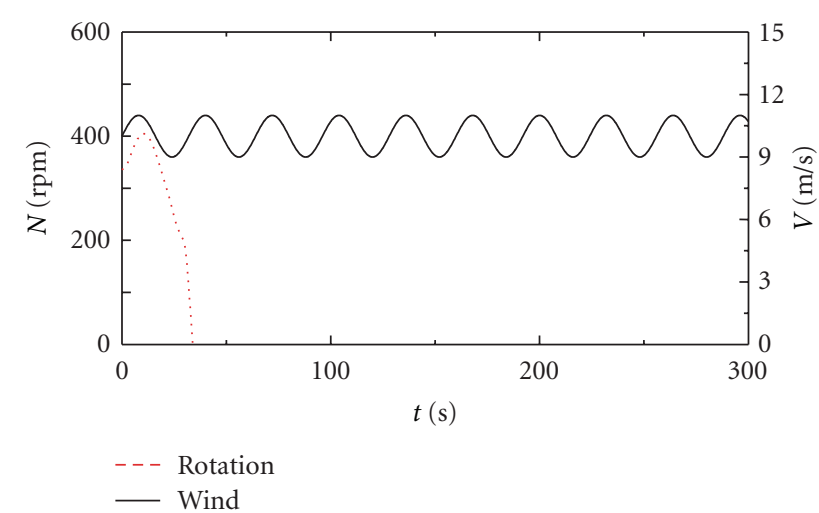

FIGURE 26: Time profile of rotational speed of pulsating wind in the case where $V_{0}=10 \mathrm{~m} / \mathrm{s}, T=32 \mathrm{~s}$, and $I=3 \mathrm{kgm}^{2}$.

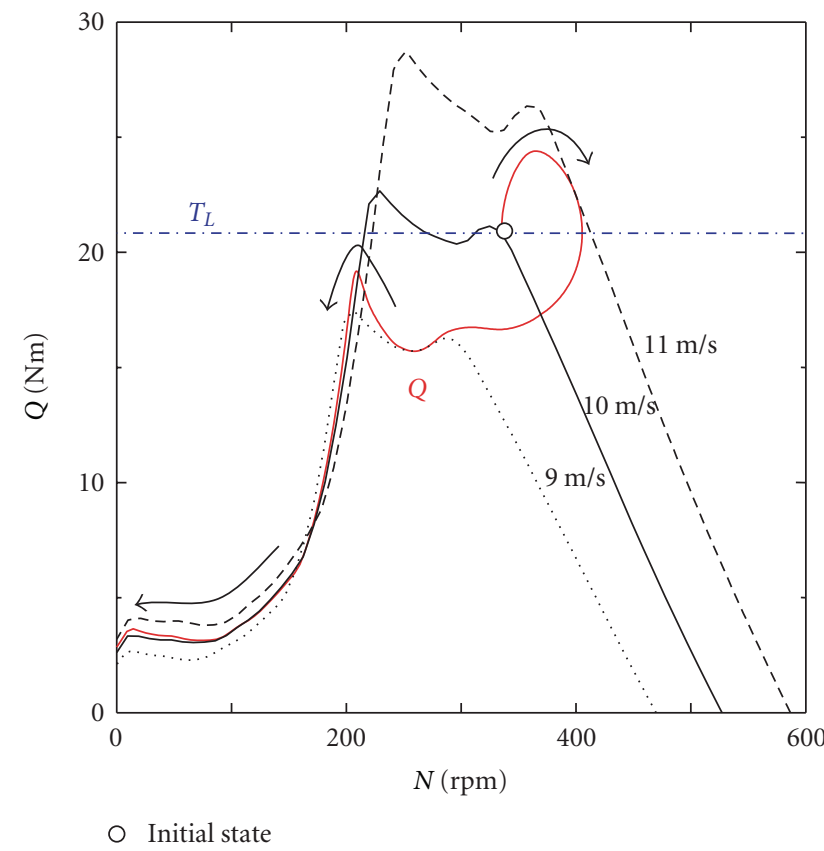

Figure 27: Locus of torque, $Q$, of pulsating wind in the case where $V_{0}=10 \mathrm{~m} / \mathrm{s}, T=32 \mathrm{~s}$, and $I=3 \mathrm{kgm}^{2}$. Constant load torque is $T_{L}=$ $20.8 \mathrm{Nm}$.

$377.1 \mathrm{rpm}$ when $I=7$ and $3 \mathrm{kgm}^{2}$, resp.), and the energy efficiency, $\eta$.

For the case where $V_{0}=10 \mathrm{~m} / \mathrm{s}, I=5 \mathrm{kgm}^{2}$, and $T=$ $16 \mathrm{~s}$, the time profile of $N$ is shown in Figure 22 and the corresponding locus of $Q$ is presented in Figure 23, and when $V_{0}=10 \mathrm{~m} / \mathrm{s}, I=5 \mathrm{kgm}^{2}$, and $T=32 \mathrm{~s}$, the time profile and locus are shown in Figures 24 and 25. Comparing between these cases, a slow change in the wind speed due to the long cycle $(T=32 \mathrm{~s})$ causes an increase in $\Delta N$ and a decrease in $N_{\text {ave }}\left(N_{\text {ave }}=299.4\right.$ and $296.2 \mathrm{rpm}$ when $T=16$ and $32 \mathrm{~s}$, resp.). As a result, $\eta$ is somewhat decreased.

As shown in Figures 21 and 25, for cases with large wind cycle and small moment of inertia, the torque locus is enlarged in the direction of the axis of the rotational speed and the energy efficiency can vary. However, the direction of the change in the energy efficiency appears to be dependent on the shape of torque curve or on the relation between $T$ and $I$.

Finally, as an example of an extreme case, the time profile of $N$ and the corresponding locus of $Q$ when $V_{0}=10 \mathrm{~m} / \mathrm{s}$, $T=32 \mathrm{~s}$, and $I=3 \mathrm{kgm}^{2}$ are shown in Figures 26 and 27, respectively. As shown in Figure 27, with a long wind cycle and a small moment of inertia, the right-hand side of (1) that is, the value $Q-T_{L}$-takes negative values after the first peak in wind speed. Therefore, the rotational speed of the wind turbine decreases $(d \omega / d t<0)$ and finally becomes zero. This unsustainable rotation condition is encountered even at larger values of $I$ if $T$ or $\Delta V$ becomes large. However, because the load torque of a wind power generator generally varies according to the rotational speed, the behavior of an actual wind turbine might be somewhat different from the present result.

\section{Conclusions}

The response of a straight-bladed VAWT to pulsating wind was investigated by changing the moment of inertia, the wind cycle, and the wind amplitude. The phase delay between the rotational speed and wind variation held a constant value, becoming approximately $\pi / 2$ when the wind amplitude was large. The rate of change in the rotational speed divided by the wind cycle, $\left(\Delta \mathrm{N} / \mathrm{N}_{\mathrm{ave}}\right) / T$, was inversely proportional to the moment of inertia and independent of the wind cycle. This result suggests a relation between the rotational speed width and pulsating wind amplitude. The energy efficiency of the VAWT in a pulsating wind with unvarying amplitude stayed almost constant under both changes in the moment of inertia and in the wind cycle, but the energy efficiency decreased when the wind amplitude was large.

Similarly, numerical simulation of a theoretical VAWT of a larger size than the experimental rotor showed that the energy efficiency was almost independent of the wind cycle and the moment of inertia under the condition of constant load torque. However, in the case of a long wind cycle and a small moment of inertia, the energy efficiency is expected to vary and is dependent on the torque curves.

\section{References}

[1] I. Paraschivoiu, Wind Turbine Design with Emphasis on Darrieus Concept, Polytechnic International Press, 2000.

[2] S. Mertens, G. van Kuik, and G. van Bussel, "Performance of an H-Darrieus in the skewed flow on a roof," Journal of Solar Energy Engineering, Transactions of the ASME, vol. 125, no. 4, pp. 433-440, 2003.

[3] G. van Bussel and S. Mertens, "Small wind turbines for the built environment," in Proceedings of the 4th European and African Conference on Wind Engineering, paper \#210, Prague, Czech, 2005.

[4] G. Marsh and S. Peace, "Tilting at windmills," Refocus, vol. 6, no. 5, pp. 37-42, 2005.

[5] J. G. Leishman, "Challenges in modelling the unsteady aerodynamics of wind turbines," Wind Energy, vol. 5, pp. 85-132, 2002. 
[6] S. Biswas, B. N. Sreedhard, and Y. P. Singh, "Dynamic analysis of a vertical axis wind turbine using a new windload estimation technique," Computers and Structures, vol. 65, no. 6, pp. 903-916, 1997.

[7] T. Hayashi, Y. Hara, T. Azui, and I. Kang, "Transient response of a vertical axis wind turbine to abrupt change of wind speed," in Proceedings of the European Wind Energy Conference and Exhibition, p. 328, Marseille, France, 2009.

[8] T. Hayashi, Y. Hara, and I. Kang et al., "Measurements of the wind generated by desert environment wind tunnel (constant speed wind and periodically varying wind)," Reports of the Faculty of Engineering, Tottori University, 2007, pp. 89-106.

[9] Y. Hara, N. Hirata, and T. Hayashi, "Visualization of an isolated vortex ring generated from step-like wind variation and the overshoot phenomenon of axial velocity," Journal of Fluid Science and Technology, vol. 6, no. 4, pp. 685-699, 2011.

[10] I. Paraschivoiu, "Aerodynamic loads and performance of the Darrieus rotor," AIAA Journal of Energy, vol. 6, no. 6, pp. 406412, 1982.

[11] R. E. Wilson and S. N. Walker, "Fixed-wake analysis of the Darrieus rotor," Sandia Report SAND81-7026, 1981.

[12] Y. Hara, "A study on low center-of-gravity wind turbine for built environment," in Proceedings of the 13th International Conference on Wind Engineering (ICWE'13), Amsterdam, The Netherlands, 2011, Paper-No.096.

[13] V. Kumar, M. Paraschivoiu, and I. Paraschivoiu, "Low Reynolds number vertical axis wind turbine for Mars," Wind Engineering, vol. 34, no. 4, pp. 461-476, 2010.

[14] R. E. Sheldahl and P. C. Klimas, "Aerodynamic characteristics of seven symmetrical airfoil sections through 180-degree angle of attack for use in aerodynamic analysis of vertical axis wind turbines," Sandia Report SAND80-2114, 1981. 

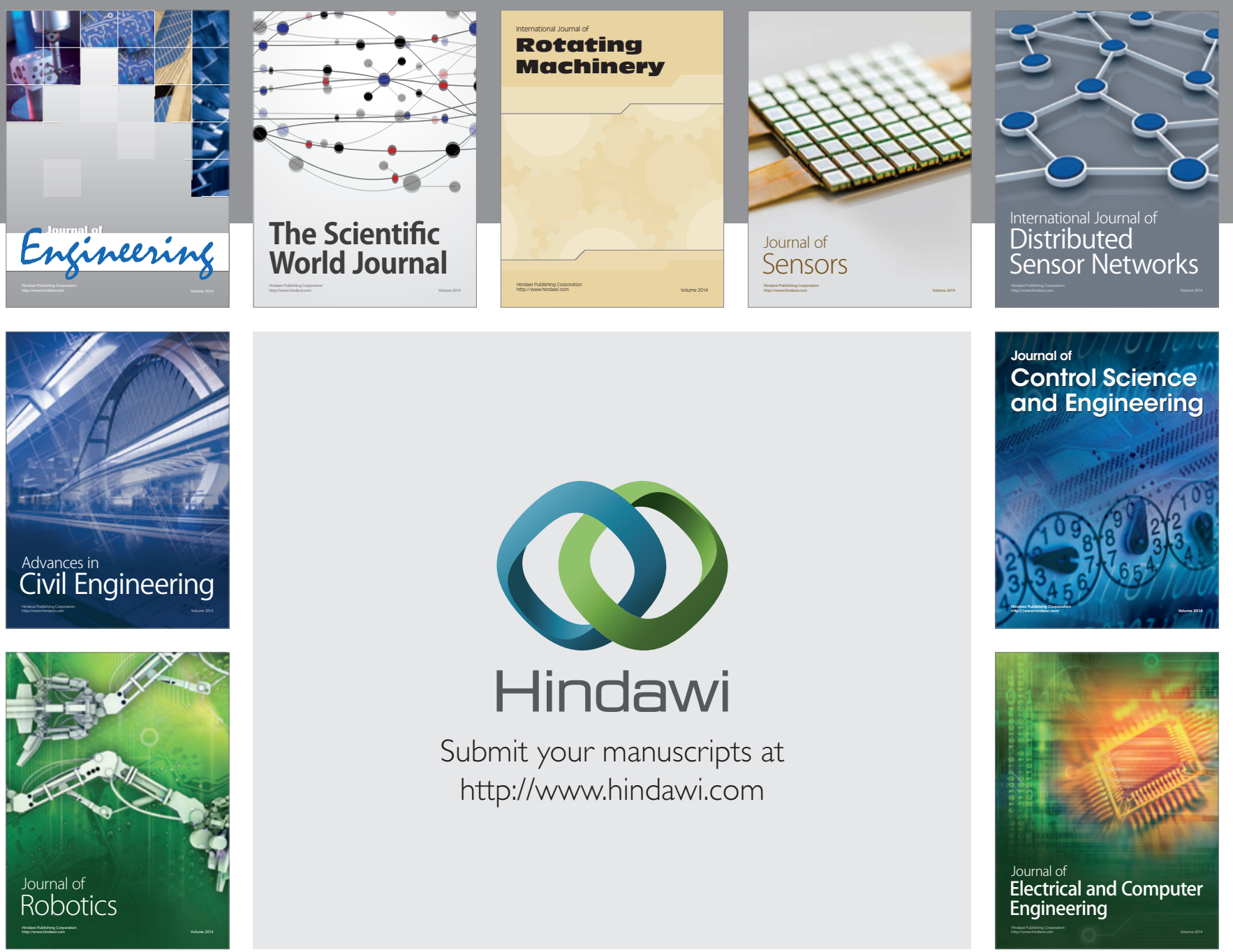

Submit your manuscripts at

http://www.hindawi.com
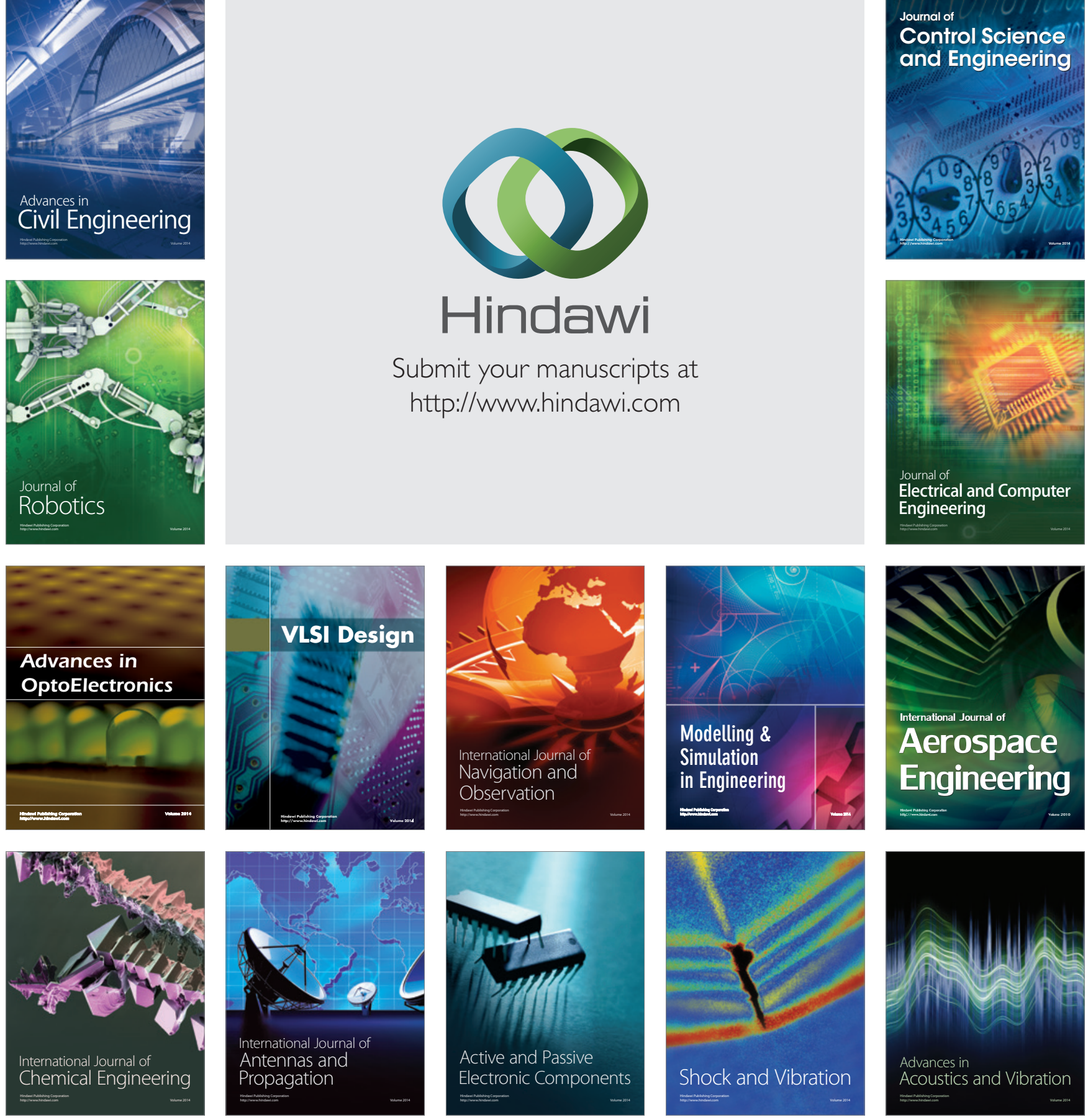